\title{
Patient Selection for Later Delivery Timing With Suspected Previa-Accreta
}

\section{Citation}

Perlman, Nicola C. 2018. Patient Selection for Later Delivery Timing With Suspected PreviaAccreta. Doctoral dissertation, Harvard Medical School.

\section{Permanent link}

http://nrs.harvard.edu/urn-3:HUL.InstRepos:41973502

\section{Terms of Use}

This article was downloaded from Harvard University's DASH repository, and is made available under the terms and conditions applicable to Other Posted Material, as set forth at http:// nrs.harvard.edu/urn-3:HUL.InstRepos:dash.current.terms-of-use\#LAA

\section{Share Your Story}

The Harvard community has made this article openly available.

Please share how this access benefits you. Submit a story.

Accessibility 
Scholarly Report submitted in partial fulfillment of the MD Degree at Harvard Medical School

Date:

22 February, 2018

Student Name:

Nicola Perlman, MA, BA

Scholarly Report Title:

PATIENT SELECTION FOR LATER DELIVERY TIMING WITH SUSPECTED PREVIAACCRETA.

Mentor Name and Affiliations: Daniela A. Carusi, MD, MSc. Director of General Gynecology, Director of Surgical Obstetrics, Assistant Professor, Harvard Medical School. Brigham and Women's Hospital.

\section{Collaborators:}

Sarah E. Little, Department of Maternal Fetal Medicine, Brigham and Women's Hospital.

David E. Cantonwine, Department of Obstetrics and Gynecology, Brigham and Women's Hospital

Ann Thomas, Department of Obstetrics and Gynecology, Brigham and Women's Hospital 


\section{Abstract \\ TITLE: Patient Selection for Later Delivery Timing with Suspected Previa- Accreta.}

Purpose: We identified patients with previa and suspected accreta who are at lowest risk of unscheduled delivery or major morbidity with planned delivery beyond 34 weeks' gestation.

Methods: This was a retrospective cohort study of patients who had reached 34.0 weeks' gestational age with a suspected previa-accreta. We evaluated rates of unscheduled and emergent delivery based on known risk factors for premature birth. In a second analysis, we stratified patients based on level of preoperative morbidity concern and evaluated rates of major transfusion and Intensive Care Unit admission by delivery week ( 34 weeks, 35 weeks or 36 weeks and beyond).

Results: Of 84 available patients, we classified 31 patients as low risk for unscheduled delivery and 52 as high risk. The low risk group was scheduled later ( 36.6 vs. 36.0 weeks; $p<0.01$ ), but demonstrated lower rates of unscheduled delivery prior to 36 weeks ( $3 \%$ vs. $19 \%, p=0.05$ ). Of the patients with no prior cesarean section, only one (7\%) experienced massive blood loss even though $36 \%$ had unscheduled deliveries. We observed no significant increase in major transfusion or massive blood loss with advancing gestational age, likely due to selection of the most concerning patients for early, scheduled delivery.

Conclusions: Patients with suspected previa-accreta and no risk factors for preterm birth are at low risk for an unscheduled delivery prior to 36 weeks. Those with no concern for percreta or increta or no prior cesarean section may also be candidates for later delivery. 


\section{Description of First Author's Contribution:}

Placenta previa-accreta is a placental implantation abnormality that is increasing in prevalence in the United States. These patients incur a great risk of morbidity at delivery. For this reason, women with prenatal evidence of previa-accreta on radiology often have a planned cesarean delivery, however there is little global consensus regarding the gestational timing of this surgery. Our study contributes to the literature on timing the delivery of placenta previa-accreta, and suggests that the optimal time for low risk patients to be delivered is around 36 weeks gestation.

The first author (NP) conceptualized the purpose and design of the study under supervision from DC and with help from SL. NP and DC created a database of patients with placenta previa-accreta diagnosed prenatally and collected all data. DC, AT, and DC conceptualized statistical models, and DC ran all statistical tests. NP drafted the manuscript under supervision from DC, and all authors contributed to editing and final revisions of the manuscript for publication.

\section{Citation for Manuscript:}

Perlman NC, Little SE, Thomas A, Cantonwine DE, Carusi DA. Patient selection for later delivery timing with suspected previa-accreta. Acta obstetricia et gynecologica Scandinavica. 2017;96(8):1021-8.

\section{Link for Manuscript:}

http://onlinelibrary.wiley.com.ezpprod1.hul.harvard.edu/doi/10.1111/aogs.13140/full 
Appendix: Published Manuscript 


\title{
Patient selection for later delivery timing with suspected previa-accreta
}

\author{
NICOLA C. PERLMAN ${ }^{1}$, SARAH E. LITTLE ${ }^{1,2}$, ANN THOMAS ${ }^{2}$, DAVID E. CANTONWINE ${ }^{1,2}$ \& \\ DANIELA A. CARUSI, ${ }^{1,2}$ \\ ${ }^{1}$ Harvard Medical School, Boston, MA, and ${ }^{2}$ Department of Obstetrics, Gynecology, and Reproductive Biology, Brigham \\ and Women's Hospital, Boston, MA, USA
}

\section{Key words \\ Placenta accreta, placenta previa, preterm delivery \\ Correspondence \\ Daniela Carusi, Department of OB/Gyn, Brigham \& Women's Hospital, 75 Francis Street, Boston, MA 02115, USA. \\ E-mail: dcarusi@bwh.harvard.edu \\ Conflict of interest \\ The authors have stated explicitly that there are no conflicts of interest in connection with this article.}

Please cite this article as: Perlman NC, Little SE, Thomas A, Cantonwine DE, Carusi DA. Patient selection for later delivery timing with suspected previa-accreta. Acta Obstet Gynecol Scand 2017; 96:1021-1028.

Received: 9 September 2016

Accepted: 28 March 2017

DOI: 10.1111/aogs.13140

\begin{abstract}
Introduction. We identified patients with previa and suspected accreta who are at lowest risk of unscheduled delivery or major morbidity with planned delivery beyond 34 weeks' gestation. Material and methods. This was a retrospective cohort study of patients who had reached 34.0 weeks' gestational age with a suspected previa-accreta. We evaluated rates of unscheduled and emergent delivery based on known risk factors for premature birth. In a second analysis, we stratified patients based on level of preoperative morbidity concern and evaluated rates of major transfusion and Intensive Care Unit admission by delivery week ( 34 weeks, 35 weeks or 36 weeks and beyond). Results. Of 84 available patients, we classified 31 patients as low risk for unscheduled delivery and 52 as high risk. The low risk group was scheduled later (36.6 vs. 36.0 weeks; $p<0.01$ ), but demonstrated lower rates of unscheduled delivery prior to 36 weeks ( $3 \%$ vs. $19 \%, p=0.05$ ). Of the patients with no prior cesarean section, only one (7\%) experienced massive blood loss even though $36 \%$ had unscheduled deliveries. We observed no significant increase in major transfusion or massive blood loss with advancing gestational age, likely due to selection of the most concerning patients for early, scheduled delivery. Conclusion. Patients with suspected previa-accreta and no risk factors for preterm birth are at low risk for an unscheduled delivery prior to 36 weeks. Those with no concern for percreta or increta or no prior cesarean section may also be candidates for later delivery.
\end{abstract}

Abbreviations: ACOG, American Congress of Obstetricians and Gynecologists; BMI, body mass index; GA, gestational age; HMR, high morbidity risk; HR, high risk; ICU, Intensive Care Unit; LMR, low morbidity risk; LRT, low risk; MMR, middle morbidity risk; NS, non-significant; PPROM, premature membrane rupture.

appropriate management recommendations (2). While obstetricians agree that a planned delivery with a multidisciplinary team is frequently warranted, there is little

Placenta accreta, a placental implantation abnormality frequently accompanied by placenta previa, occurs in approximately one in 500 pregnancies (1-3). These patients incur a high risk of morbidity, including massive blood loss during delivery, hysterectomy, and Intensive Care Unit (ICU) admission (4-9). Recent reviews have suggested an increasing prevalence of placenta previa-accreta and a growing demand for

\section{Key Message}

Women with suspected placenta previa-accreta, no risk factors for preterm birth, and low suspicion for deep invasion may qualify for later delivery. 
data to guide the timing of delivery for previa-accreta patients $(10,11)$.

Currently, the American Congress of Obstetricians and Gynecologists (ACOG) recommends a 34-week scheduled cesarean delivery based on a decision analysis performed in 2010 (3,4,12). ACOG acknowledges that delivery timing for accreta patients needs to be individualized, though they give no specific guidelines. Similarly, the The Eunice Kennedy Shriver National Institute of Child Health and Human Development (NICHD) suggests delivery at $34^{0 / 7}$ weeks to $35^{6 / 7}$ weeks based on recommendations from one review showing emergent delivery rates for previaaccreta reaching close to $50 \%(13,14)$. Alternatively, the Royal College of Obstetricians and Gynaecologists (RCOG) does not recommend delivery for asymptomatic women before 36-37 weeks' gestation (15). No consensus between organizations exists.

Arguments for an early delivery include avoiding unnecessary maternal morbidity, such as emergency hemorrhage, and having ample time to assemble a multidisciplinary team $(4,16)$. Robinson's 2010 recommendation was based on the premise that unscheduled and emergent deliveries for these patients will increase morbidity. Others may plan earlier deliveries under the assumption that placental invasion or the degree of vascularity may worsen with increasing gestation. However, recent studies have questioned the assumption that more blood loss occurs with delayed delivery (17), and others have emphasized adverse outcomes in infants of women with placental implantation abnormalities delivered prematurely, including neonatal ICU admission and premature lung development (8).

The objective of the current study was to provide guidance for individualized patient care. Our first question was whether known risk factors for preterm birth can predict an unscheduled or emergent delivery, allowing later scheduling for those at lowest risk. Secondly, we compared maternal outcomes based on delivery at increasing gestational ages, separately evaluating patients at highest and lowest anticipated hemorrhage risk. We hypothesized that unscheduled delivery, surgical complexity, and hemorrhage due to placental invasion and hypervascularity drive delivery morbidity. Therefore, patients at low risk for these outcomes may have more conservatively timed deliveries, whereas those at higher risk may benefit from an earlier planned delivery.

\section{Material and methods}

This retrospective cohort study was approved by the Institutional Review Boards at Partners Healthcare and Harvard Medical School (IRB 2014P001275, approved 25 June 14). We collected all deliveries occurring at Brigham and Women's Hospital in Boston, MA, between January
1997 and December 2014, including patients with radiographic evidence of placenta previa and suspicion for accreta delivered at or beyond 34 weeks' gestation. Brigham and Women's Hospital is a tertiary, academic medical center with 24-h access to specialists. The hospital has no formal delivery planning policy for patients with previa or accreta, and delivery timing was left to the discretion of individual providers.

Patient data were collected from electronic and paper charts. Two authors (N.P. and D.C.) reviewed ultrasound and MRI reports for all patients. Placenta previa at delivery was defined as the placental edge coming within $2 \mathrm{~cm}$ of the cervical os. Suspected accreta, increta or percreta was made by radiographic diagnosis if on ultrasound or MRI the radiologist reported suspicion for accreta due to vascular lakes, myometrial thinning, loss of sonolucent zone, bulging mass or hypervascularity. For the last criterion, notation was made as to whether it was present at or after 28 weeks' gestation. Patients with radiologic report of suspected accreta without more detail on specific findings were also included. However, if the radiologist read the findings as "cannot rule out" accreta, with no greater diagnostic certainty, the patient was excluded.

To analyze morbidity based on scheduled delivery timing, eligible patients were divided into three categories: those with deliveries planned at 34 weeks $\left(34^{0 / 7}-34^{6 / 7}\right.$ weeks' gestation), 35 weeks $\left(35^{0 / 7}-35^{6 / 7}\right.$ weeks) or $36+$ weeks ( $36^{0 / 7}$ weeks and after). Providers determined gestational dating based on last menstrual period, or via earliest ultrasound if the last menstrual period was unknown, unreliable, or a discrepancy existed between last menstrual period and ultrasound dating.

We collected detailed demographic and medical data for each subject, including specific medical comorbidities (chronic hypertension, diabetes, cardiac or hematologic disease, or anticoagulation). To evaluate the impact of later delivery timing on the ability to assemble a multidisciplinary team, we evaluated differences in surgical preparation and intervention during surgery.

Primary outcome measures included rates of emergent or unscheduled delivery and immediate maternal morbidity. A delivery was considered emergent if it was performed for maternal or fetal instability and occurred within one hour of the decision to deliver. A delivery was considered unscheduled if performed ahead of the scheduled delivery date due to a change in clinical status, and occurred within $24 \mathrm{~h}$. Major blood loss was defined as greater than 4 units of packed red blood cells transfused, and massive hemorrhage as greater than or equal to 5 liters estimated blood loss or 10 or more units red blood cell transfusion (18).

To group patients based on the potential for morbidity, we first stratified patients based on risk factors for 
unscheduled delivery prior to 36 weeks. Stratification criteria included bleeding or preterm labor prior to 34 weeks, premature membrane rupture (PPROM), or a known risk factor for preterm delivery (prior spontaneous preterm birth, any cervical length measurement $<2.5 \mathrm{~cm}$, or multiple gestations). Patients with any of these risk factors were labeled high risk (HR), and all others called low risk (LR). In a separate analysis, we stratified subjects based on level of concern for morbid accreta. Any patient with no prior cesarean section was considered to be at lowest morbidity risk (LMR), whereas those with radiographic signs of increta, percreta or hypervascularity in the third trimester were considered to be at highest morbidity risk (HMR). All others (radiographic signs of accreta, no third trimester hypervascularity, and at least one prior cesarean section) were considered to be at mid-level risk (MMR). The association between gestational age (GA) at delivery and maternal morbidity was assessed separately for each risk group.

Statistical analyses were conducted using Statistical Analysis Software version 9.4 (SAS Institute, Cary, NC, USA). Categorical variables were compared with Fisher Exact or Chi-square tests, where appropriate, and continuous variables were analyzed with Kruskal-Wallis tests. All results were considered significant at $p<0.05$ with two-tailed analyses.

\section{Results}

Women with antenatal radiographic evidence of placenta previa and suspected accreta $(n=124)$ were identified between January 1997 and December 2014, of whom 96 (77\%) reached $34^{0 / 7}$ weeks GA. Twelve of these remaining women were excluded due to uncertain radiologic evidence of placenta accreta (reported as "cannot rule out" accreta), leaving 84 subjects for the analysis.

Of our 84 patients, the majority $(69 \%)$ were scheduled at $36+$ weeks, with only $11(13 \%)$ scheduled at 34 weeks, and $15(18 \%)$ at 35 weeks. Characteristics and outcomes of groups based on GA at delivery are shown in Table 1. Baseline maternal characteristics, including age, BMI, race, and medical history, did not differ by delivery week. The 34 weeks' group showed higher rates of gestational hypertension than the 35 weeks and later groups $(19 \%$ vs. $6 \%$ and $2 \%$, respectively, $p=0.03)$. This group also exhibited more risk factors for unscheduled delivery, including antepartum bleeding before the $34^{\text {th }}$ week of gestation $(94 \%$ vs. $65 \%$ and $41 \%, p<0.01)$, prior preterm birth $(27 \%$ vs. 0 vs. $12 \%, p=0.07)$, and multiple gestations $(19 \%$ of those delivered at 34 weeks, with none delivered later, $p<0.01)$. Delivery setup did not differ significantly by week of delivery.
Our first analysis focused on risk factors for unscheduled delivery, which were identified in 52 subjects (62\%). One patient had incomplete antenatal records prohibiting accurate categorization, and was excluded from this analysis. Characteristics for our risk-stratified groups are shown in Table 2. Of note, $90 \%$ of the patients in the HR group experienced antepartum bleeding prior to 34 weeks' gestation, with $62 \%$ in the third trimester. Deliveries were scheduled significantly later for the LR group (median 36.6 vs. 36.0 weeks, $p<0.01$ ), while the HR patients had a higher rate of antepartum steroid administration, but no difference in the rate of gestational hypertension or preeclampsia.

The delivery outcomes for the LR vs. HR groups are shown in Table 3. The median GA at delivery was onehalf week later for the LR patients (36.4 vs. 35.9 weeks, $p$ $<0.01)$. The LR group was less likely to undergo an unscheduled delivery prior to 36 weeks (3 vs. 19\%, $p=0.05$ ), with only one patient in the LR group experiencing a non-emergent, unscheduled delivery at 35 weeks. Both emergent deliveries occurred in the HR group, and occurred in patients scheduled at $36+$ weeks. Rates of major transfusion, massive blood loss, and ICU admission were highly similar between the two risk groups. The prenatal diagnosis of accreta was confirmed pathologically in $59 \%$ of LR patients vs. $77 \%$ of HR patients (non-significant, NS). Five patients in the LR group experienced massive blood loss, four of whom had a confirmed pathologic percreta. The fifth had an accreta identified at the site of prior uterine rupture, and underwent an anticipated difficult delivery.

For our second analysis, we evaluated the maternal morbidity according to delivery week, with patients stratified by antepartum level of concern for a morbid accreta (Table 4). Upon reviewing our data, we found that no patient was scheduled for a 34-week delivery prior to 2005, and descriptions of hypervascularity in the lower uterus were not used until 2004. Therefore, we restricted this second analysis to 2005 and later $(n=63)$. The highrisk group (HMR, $n=19$, Table 4c) was scheduled for delivery at a median of 35.7 weeks GA, and those in the low risk (LMR, $n=14$, Table $4 \mathrm{a}$ ) and medium risk (MMR, $n=30$, Table $4 \mathrm{~b}$ ) groups were scheduled at median of 36.0 and 36.3 weeks, respectively $(p=0.08)$.

We observed no trend towards increased morbidity with advancing gestational age, regardless of morbidity risk category. In contrast, we observed a trend towards more ICU admissions with earlier deliveries in the MMR group, with a $5 \%$ rate at $36+$ weeks vs. $40 \%$ and $33 \%$ at 34 and 35 weeks, respectively $(p=0.05)$. Both the LMR and HMR groups showed lower rates of hysterectomy at $36+$ weeks than at earlier gestational ages, which was significant for the HMR group $(p=0.04)$. 
Table 1. Patient characteristics and outcomes based on gestational age at delivery.

\begin{tabular}{|c|c|c|c|c|}
\hline & 34 weeks $n=16$ & 35 weeks $n=17$ & $36+$ weeks $n=51$ & $p$-value \\
\hline \multicolumn{5}{|l|}{ Maternal and obstetric characteristics } \\
\hline Maternal age at delivery (years) & $35.0(28.6-39.8)$ & $35.8(24.6-51.3)$ & $35.7(23.3-44.3)$ & 0.96 \\
\hline Maternal BMI $\left(\mathrm{kg} / \mathrm{m}^{2}\right)$ & $29.5(23-41)$ & $28(22-50)$ & $28(21-54)$ & 0.95 \\
\hline White race & $12(75 \%)$ & $11(65 \%)$ & $31(61 \%)$ & 0.66 \\
\hline Parity & $1.5(0-6)$ & $2(0-4)$ & $2(0-4)$ & 0.96 \\
\hline Prior cesarean section & $11(69 \%)$ & $13(76 \%)$ & $44(86 \%)$ & 0.22 \\
\hline Prior uterine surgery & $7(44 \%)$ & $5(29 \%)$ & $18(35 \%)$ & 0.69 \\
\hline Maternal medical disease & $1(6 \%)$ & $1(6 \%)$ & $5(10 \%)$ & 1.0 \\
\hline Uterine fibroids & $1(6 \%)$ & $4(24 \%)$ & $9(18 \%)$ & 0.42 \\
\hline ART pregnancy & $3(19 \%)$ & $4(24 \%)$ & $7(14 \%)$ & 0.6 \\
\hline Gestational HTN or preeclampsia & $3(19 \%)$ & $1(6 \%)$ & $1(2 \%)$ & 0.03 \\
\hline \multicolumn{5}{|l|}{ Categorization factors } \\
\hline PPROM <34 weeks & $1(6 \%)$ & 0 & 0 & 0.19 \\
\hline Preterm labor $<34$ weeks & $1(6 \%)$ & $1(6 \%)$ & $3(6 \%)$ & 1.0 \\
\hline Antepartum bleeding $<34$ weeks & $15(94 \%)$ & $11(65 \%)$ & $20(41 \%)$ & $<0.01$ \\
\hline PTD risk factor: any & $6(38 \%)$ & $2(12 \%)$ & $8(16 \%)$ & 0.13 \\
\hline Cervical length $<2.5 \mathrm{~cm}$ & $2(13 \%)$ & $2(15 \%)$ & $2(6 \%)$ & 0.61 \\
\hline Multiple gestations & $3(19 \%)$ & 0 & 0 & $<0.01$ \\
\hline Prior preterm birth & $4(27 \%)$ & 0 & $6(12 \%)$ & 0.07 \\
\hline \multicolumn{5}{|l|}{ Level of morbidity concern ${ }^{a}$} \\
\hline Suspected increta/percreta & $4(25 \%)$ & $5(29 \%)$ & $10(20 \%)$ & 0.77 \\
\hline Suspected accreta with hypervascular LUS & $4(25 \%)$ & $3(18 \%)$ & $6(12 \%)$ & 0.33 \\
\hline \multicolumn{5}{|l|}{ Operative setup and performance } \\
\hline Oncologist at start of case & $3(19 \%)$ & $3(18 \%)$ & $3(6 \%)$ & 0.14 \\
\hline Preoperative hypogastric artery balloon placement & $2(13 \%)$ & $4(24 \%)$ & $15(29 \%)$ & 0.46 \\
\hline Hypogastric balloon inflation & $2(13 \%)$ & $3(18 \%)$ & $12(24 \%)$ & 0.69 \\
\hline Placental removal ${ }^{\mathrm{b}}$ & $7(44 \%)$ & $11(65 \%)$ & $35(69 \%)$ & 0.21 \\
\hline
\end{tabular}

ART, assisted reproductive technology; HTN, hypertension; PPROM, preterm premature rupture of the membranes; PTD, preterm delivery; LUS, lower uterine segment.

Results are expressed as $n$ (\%) or median (range).

${ }^{a}$ Based on ultrasound and MRI reports. Hypervascular LUS as noted on third trimester imaging.

${ }^{\mathrm{b}}$ Refers to removal of any part of the placenta.

Both the LMR and MMR groups demonstrated significantly more unscheduled deliveries at the earlier GA categories ( $p=0.03$ in both groups). The overall rate of either ICU admission or massive blood loss was $18 \%$ for those undergoing a scheduled delivery and $14 \%$ for those with an unscheduled cesarean, a non-significant difference $(p=1.0)$. Notably, the LMR group experienced no ICU admissions and only one massive blood loss (7\%) in a patient with a hypervascular lower uterus, though five of $14(36 \%)$ had an unscheduled delivery. Alternatively, only one patient in the HMR group (5\%) had a delivery that was unscheduled, whereas four $(21 \%)$ experienced one of these major morbidities.

\section{Discussion}

The ACOG and NICHD recommendations for previaaccreta delivery at 34 or 35 weeks' gestation arose from the assumption that maternal morbidity, including but not limited to massive hemorrhage and ICU admission, increases with GA $(4,7,19)$. Here we describe a cohort of patients with previa and suspected accreta in which more than half were delivered at 36 weeks or later. Our relatively low rates of massive hemorrhage and ICU admission likely reflect patient selection for early vs. later delivery, supporting the ACOG suggestion that delivery timing should be individualized.

In our primary analysis, using a priori criteria, we successfully stratified patients according to their risk for unscheduled delivery. Almost all of our low-risk patients, with no risk factors for preterm delivery, were scheduled at 36 weeks or later. None of these patients underwent an emergency delivery, and only one had an unscheduled delivery prior to 36 weeks. We separately stratified patients based on antepartum concern for a morbid delivery, finding that those with no prior cesarean section, particularly in the absence of sonographic hypervascularity, had very good outcomes. These patients, and those with lower antepartum diagnostic certainty, may also be appropriate for later delivery timing. 
Table 2. Characteristics of patients at low or high risk of unscheduled delivery.

\begin{tabular}{|c|c|c|c|}
\hline Variable & Low risk $(\mathrm{LR}) n=31$ & High risk $(\mathrm{HR}) n=52^{\mathrm{a}}$ & $p$-value \\
\hline \multicolumn{4}{|l|}{ Maternal and obstetric characteristics } \\
\hline Maternal age at delivery (years) & $36.3(31.8-51.3)$ & $35.0(23.3-43.6)$ & 0.01 \\
\hline Maternal BMI $\left(\mathrm{kg} / \mathrm{m}^{2}\right)$ & $27(23-54)$ & $29.0(21.0-50.0)$ & 0.16 \\
\hline White race & $20(65 \%)$ & $33(63 \%)$ & 1 \\
\hline Parity & $1(0-4)$ & $2(0-6)$ & 0.46 \\
\hline Prior cesarean section & $25(81 \%)$ & $42(81 \%)$ & 1 \\
\hline Prior uterine surgery & $6(19 \%)$ & $24(46 \%)$ & 0.02 \\
\hline Maternal medical disease & $2(6 \%)$ & $5(10 \%)$ & 0.71 \\
\hline Fibroids & $1(3 \%)$ & $13(25 \%)$ & 0.01 \\
\hline ART pregnancy & $7(23 \%)$ & $7(13 \%)$ & 0.37 \\
\hline Gestational HTN or preeclampsia & $1(3 \%)$ & $4(8 \%)$ & 0.65 \\
\hline Any antepartum admission & $5(16 \%)$ & $35(67 \%)$ & $<0.01$ \\
\hline Antepartum steroids & $12(39 \%)$ & $42(81 \%)$ & $<0.01$ \\
\hline Fetal anomalies & $2(6 \%)$ & $4(8 \%)$ & 1 \\
\hline Scheduled gestational age & $36.6(35.0-38.6)$ & $36.0(34.0-38.0)$ & $<0.01$ \\
\hline \multicolumn{4}{|l|}{ Level of morbidity concern ${ }^{a}$} \\
\hline Suspected increta/percreta & $5(16 \%)$ & $14(27 \%)$ & 0.55 \\
\hline Suspected accreta with hypervascular LUS & $6(19 \%)$ & $7(13 \%)$ & 0.54 \\
\hline
\end{tabular}

ART, assisted reproductive technology; HTN, hypertension; LUS, lower uterine segment.

High risk (HR) criteria include any known risk factor for preterm birth (multiple gestations, cervical length $<2.5 \mathrm{~cm}$, or prior spontaneous preterm birth), or bleeding, preterm labor, or PPROM prior to 34 weeks. Results are reported as $n$ (\%), or as median (range) for continuous variables.

aBased on ultrasound and MRI reports. Hypervascular LUS as noted on third trimester imaging.

Table 3. Maternal outcomes for patients at low or high risk for unscheduled delivery.

\begin{tabular}{|c|c|c|c|}
\hline Outcome & $\begin{array}{l}\text { Low risk (LR) } \\
n=31\end{array}$ & $\begin{array}{l}\text { High Risk (HR) } \\
n=52\end{array}$ & $\begin{array}{l}p \text { - } \\
\text { value }\end{array}$ \\
\hline $\begin{array}{l}\text { Unscheduled } \\
\text { delivery }<36 \text { weeks }\end{array}$ & $1(3 \%)$ & $10(19 \%)$ & 0.05 \\
\hline Emergent delivery & 0 & $2(4 \%)$ & 0.53 \\
\hline $\begin{array}{l}\text { Gestational age at } \\
\text { delivery }\end{array}$ & $36.4(35.0-38.4)$ & $35.9(34.0-38.0)$ & $<0.01$ \\
\hline Major transfusion ${ }^{a}$ & $8(26 \%)$ & $14(27 \%)$ & 1.0 \\
\hline ICU admission & $3(10 \%)$ & $4(8 \%)$ & 1.0 \\
\hline Massive blood loss & $5(16 \%)$ & $9(17 \%)$ & 1.0 \\
\hline Hysterectomy & $18(58 \%)$ & $37(71 \%)$ & 0.24 \\
\hline Pathologic accreta ${ }^{c}$ & $17 / 29(59 \%)$ & $37 / 48(77 \%)$ & 0.12 \\
\hline
\end{tabular}

Results are reported as $n(\%)$ for categorical, or as median (range) for continuous variables.

${ }^{a}$ Major transfusion includes more than 4 units of packed red blood cells.

${ }^{\mathrm{b}}$ Massive blood loss is more than 5 liters estimated blood loss or $\geq 10$ units red blood cells transfused.

'The denominator includes only subjects for whom the uterus and/or placenta was sent for pathologic analysis. This includes any level of placental attachment or invasion.

We failed to observe increased morbidity with advancing GA at delivery, which may, in part, be due to patient selection factors. In our secondary analysis, we attempted to define these factors retrospectively using cesarean section history and notations of deep invasion or hypervascularity on radiology reports. Given that we observed trends towards more ICU admissions and more hysterectomies with earlier deliveries, we feel that providers managed patients using risk assessments not captured by our definitions. Although unscheduled deliveries were more common at 34 or 35 weeks in our lower-risk groups, this did not account for higher morbidity, as we observed no relation between unscheduled delivery status and major morbidity. However, the finding of only one unscheduled delivery in our highest morbidity patients suggests that unscheduled delivery risk factors were most often applied to this group. We might have observed a different pattern of morbidity, had all of these patients been scheduled later.

Our study has the strength of evaluating patients who were largely scheduled, regardless of risk categorization, at 36 weeks or later. This allowed us to observe expectant management outcomes in the 34th and 35th weeks of gestation. We also benefited from including a realistic cohort of patients with suspected previa-accreta in our recommendations regarding delivery timing. Other studies of accreta morbidity have excluded false positives based on radiology and included only women with pathologically confirmed accreta, but it is not possible to have that confirmation during delivery planning $(18,20)$. Given that the positive predictive value for radiographically suspected accreta is only about $80 \%$, excess prematurity based on a false-positive diagnosis needs to be considered a risk of early delivery timing $(21,22)$. 
Table 4. Maternal morbidity outcomes by week of delivery, stratified by preoperative concern for morbidity risk.

\begin{tabular}{|c|c|c|c|c|}
\hline $\begin{array}{l}\text { (a) Low morbidity risk (LMR) } \\
\text { Outcome }\end{array}$ & 34 weeks $n=5$ & 35 weeks $n=4$ & 36 weeks $n=5$ & $p$-value \\
\hline High volume transfusion ${ }^{a}$ & $1(20 \%)$ & $1(25 \%)$ & 0 & 0.73 \\
\hline ICU admission & 0 & 0 & 0 & 1.0 \\
\hline Massive blood loss ${ }^{\mathrm{b}}$ & $1(20 \%)$ & 0 & 0 & 1.0 \\
\hline Hysterectomy & $4(80 \%)$ & $1(25 \%)$ & $1(20 \%)$ & 0.03 \\
\hline Unscheduled delivery & $4(80 \%)$ & $1(25 \%)$ & 0 & 0.03 \\
\hline Pathological accreta confirmation ${ }^{c}$ & $4 / 5(80 \%)$ & $1 / 4(25 \%)$ & $2 / 5(40 \%)$ & 0.42 \\
\hline
\end{tabular}

(b) Middle morbidity risk (MMR)

\begin{tabular}{|c|c|c|c|c|}
\hline Outcomes & 34 weeks $n=5$ & 35 weeks $n=3$ & 36 weeks $n=22$ & $p$-value \\
\hline High volume transfusion ${ }^{a}$ & $3(60 \%)$ & $1(33 \%)$ & $5(23 \%)$ & 0.29 \\
\hline ICU admission & $2(40 \%)$ & $1(33 \%)$ & $1(5 \%)$ & 0.05 \\
\hline Massive blood loss ${ }^{\mathrm{b}}$ & $2(40 \%)$ & $1(33 \%)$ & $2(9 \%)$ & 0.13 \\
\hline Hysterectomy & $4(80 \%)$ & $2(67 \%)$ & $16(73 \%)$ & 1.0 \\
\hline Unscheduled delivery & $3(60 \%)$ & $2(67 \%)$ & $3(14 \%)$ & 0.03 \\
\hline Pathologic accreta confirmation ${ }^{c}$ & $4 / 5(80 \%)$ & $3 / 3(100 \%)$ & $14 / 20(70 \%)$ & 0.08 \\
\hline
\end{tabular}

(c) High morbidity risk (HMR)

Outcome 34 weeks $n=6$

\begin{tabular}{|c|c|c|c|c|}
\hline High volume transfusion ${ }^{a}$ & $2(33 \%)$ & $2(29 \%)$ & $2(33 \%)$ & 1.0 \\
\hline ICU admission & 0 & $1(14 \%)$ & 0 & 1.0 \\
\hline Massive blood loss ${ }^{b}$ & $2(33 \%)$ & $2(29 \%)$ & 0 & 0.48 \\
\hline Hysterectomy & $6(100 \%)$ & $7(100 \%)$ & $3(50 \%)$ & 0.04 \\
\hline Unscheduled delivery & 0 & $1(14 \%)$ & 0 & 1.0 \\
\hline Pathological accreta confirmation ${ }^{c}$ & $5 / 6(83 \%)$ & $7 / 7(100 \%)$ & $3 / 6(50 \%)$ & 0.08 \\
\hline
\end{tabular}

Results are reported as $n$ (\%). Statistical analysis completed with Fisher Exact tests. Low morbidity risk (LMR) includes all patients with no prior cesarean section. High morbidity risk includes those with radiographically suspected increta or percreta or a hypervascular lower segment on third trimester imaging. Medium morbidity risk (MMR) includes all other patients.

${ }^{a}$ Major transfusion includes more than 4 units of packed red blood cells.

${ }^{b}$ Massive blood loss is more than 5 liters estimated blood loss or $\geq 10$ units red blood cells transfused.

'The denominator includes only subjects for whom the uterus and/or placenta was sent for pathologic analysis.

Our study was limited by the low incidence of previaaccreta, restricting the power of our sub-analyses. The cohort was collected retrospectively, spanning an 18-year period, with variable providers and practice patterns, and therefore the motivations for delivery planning could not always be inferred. Details of radiographic findings were not reported systematically, and original images were not always available for review. Therefore, we could not always formalize the strength of the radiologic descriptions in hindsight, and were required to limit the use of this data to the later years of the study, when more detailed descriptions were used. Larger studies of delivery timing for previa-accreta are lacking in the literature, and thus a prospective, multicenter study with a uniform protocol is needed (23). Further research also should elucidate additional predictors of maternal morbidity, including specific antenatal findings and surgical technique, which may be useful for delivery planning.
Our results emphasize the importance of individualized patient care in the context of suspected accreta. Published recommendations for delivery timing give uniform guidance for all previa-accreta patients, with no mention of antepartum course, suspected degree of placental invasion, or patient history. Though ACOG acknowledges individualized patient planning, no specific clinical guidelines for individualization are suggested (3). With this study, we have defined characteristics for a low-risk group of patients who demonstrate little major morbidity despite having their deliveries scheduled at 36 weeks and later.

Our results should be interpreted in the context of the delivering institution, and its ability to minimize morbidity with previa-accreta surgery. Robinson and Grobman's 2010 decision analysis, from which ACOG recommendations are drawn, assumed high rates of maternal morbidity as GA progresses, including a $36 \%$ rate of ICU admission, $11 \%$ rate of emergent delivery for hemorrhage, 
and $0.6 \%$ incidence of perinatal mortality (4). Actual rates of morbidity likely depend on both patient and institutional factors, which should be taken into account. Within our cohort, the rates of these morbidities were 8 , 2 , and $0 \%$, respectively. Interestingly, the 2010 decision analysis showed that when a low rate of emergency hemorrhage was assumed (2-8\%), the preferred timing strategy would be a 37-week delivery (4). Other tertiary centers have shown similarly low rates of morbidity with scheduled and unscheduled accreta deliveries, likely reflecting the ability of an individual institution to assemble a surgical team on short notice $(17,19)$. We acknowledge that the low morbidity rates in these retrospective studies likely reflect patient selection, and we offer initial guidance for triaging suspected accreta patients at a tertiary medical center.

We conclude that individual risk stratification, in the context of institutional capabilities, is an essential component of accreta delivery planning. In a hospital equipped for accreta care, selected, stable previa-accreta patients can be considered for delivery at gestational ages beyond 34 and 35 weeks without increased maternal morbidity. It is important to consider the false-positive preoperative accreta diagnoses, which were highest both for women with no prior history of cesarean section and for those with no risk factors for preterm delivery. Delaying delivery for these groups, as well as those with lower diagnostic certainty, will help to reduce unnecessary neonatal risks of prematurity. Later timing for those with a prior cesarean history and concern for accreta should be managed by clinicians experienced in radiograph interpretation, preoperative planning, and surgical management. Those with suspected percreta or a hypervascular lower uterus may be the most appropriate for early delivery planning, particularly with a bleeding history or risk factors for spontaneous preterm birth.

Ideally, we would deliver patients at the GA at which the lowest morbidity for the mother coincides with lowest morbidity for the infant. As the second leading cause of iatrogenic prematurity, efforts should be made to restrict the earliest planned previa-accreta deliveries to situations with demonstrated benefit (8). While awaiting more research, individualized care that considers diagnostic certainty, maternal risk for complicated surgery and unscheduled delivery, and patient access to an experienced tertiary care center may be the first step towards reducing unnecessary, accreta-related prematurity.

\section{Acknowledgments}

The authors would like to acknowledge Ms Mary De Pari, who assisted with database management, and Ms Bernadette Aidonidis, who helped with data collection.

\section{Funding}

Partially funded by the Scholars in Medicine Program, Harvard Medical School, and the Department of Obstetrics, Gynecology \& Reproductive Biology, Brigham \& Women's Hospital.

\section{References}

1. Wu S, Kocherginsky M, Hibbard JU. Abnormal placentation: twenty-year analysis. Am J Obstet Gynecol. 2005;192:1458-61.

2. Higgins MF, Monteith C, Foley M, O’Herlihy C. Real increasing incidence of hysterectomy for placenta accreta following previous caesarean section. Eur J Obstet Gynecol Reprod Biol. 2013;171:54-6.

3. Placenta Accreta. Committee Opinion No. 529. American College of Obstetricians and Gynecologists. Obstet Gynecol 2012;120:207-11.

4. Robinson BK, Grobman WA. Effectiveness of timing strategies for delivery of individuals with placenta previa and accreta. Obstet Gynecol. 2010;116:835-42.

5. Al-Khan A, Gupta V, Illsley NP, Mannion C, Koenig C, Bogomol A, et al. Maternal and fetal outcomes in placenta accreta after institution of team-managed care. Reprod Sci. 2014;21:761-71.

6. Balayla J, Bondarenko HD. Placenta accreta and the risk of adverse maternal and neonatal outcomes. J Perinat Med. 2013;41:141-9.

7. Eshkoli T, Weintraub AY, Sergienko R, Sheiner E. Placenta accreta: risk factors, perinatal outcomes, and consequences for subsequent births. Am J Obstet Gynecol 2013;208:219.e1-7.

8. Vahanian SA, Lavery JA, Ananth CV, Vintzileos A. Placental implantation abnormalities and risk of preterm delivery: a systematic review and metaanalysis. Am J Obstet Gynecol. 2015;213:S78-90.

9. Miller DA, Chollet JA, Goodwin TM. Clinical risk factors for placenta previa-placenta accreta. Am J Obstet Gynecol. 1997;177:210-4.

10. Fitzpatrick KE, Sellers S, Spark P, Kurinczuk JJ, Brocklehurst P, Knight M. The management and outcomes of placenta accreta, increta, and percreta in the UK: a population-based descriptive study. BJOG 2014;121:62-70; discussion 70-1.

11. Doumouchtsis SK, Arulkumaran S. The morbidly adherent placenta: an overview of management options. Acta Obstet Gynecol Scand. 2010;89:1126-33.

12. Grobman WA, Gersnoviez R, Landon MB, Spong CY, Leveno KJ, Rouse DJ, et al. Pregnancy outcomes for women with placenta previa in relation to the number of prior cesarean deliveries. Obstet Gynecol. 2007;110:1249-55.

13. Warshak CR, Ramos GA, Eskander R, Benirschke K, Saenz CC, Kelly TF, et al. Effect of predelivery diagnosis in 99 
consecutive cases of placenta accreta. Obstet Gynecol. 2010;115:65-9.

14. Spong CY, Mercer BM, D’alton M, Kilpatrick S, Blackwell $\mathrm{S}$, Saade G. Timing of indicated late-preterm and earlyterm birth. Obstet Gynecol 2011;118:323-33.

15. Royal College of Obstetricians and Gynaecologists.

Placenta praevia, placenta praevia accreta and vasa praevia: diagnosis and management (Green-top 27) [Internet]. London: The Royal College of Obstetricians and Gynaecologists, 2011. Available online at: https://www.rc og.org.uk/globalassets/documents/guidelines/gtg_27.pdf. (accessed 4 May, 2017).

16. Wortman AC, Alexander JM. Placenta accreta, increta, and percreta. Obstet Gynecol Clin North Am. 2013;40:137-54.

17. Rac MW, Wells CE, Twickler DM, Moschos E, McIntire DD, Dashe JS. Placenta accreta and vaginal bleeding according to gestational age at delivery. Obstet Gynecol. 2015;125:808-13.

18. Wright JD, Pri-Paz S, Herzog TJ, Shah M, Bonanno C, Lewin SN, et al. Predictors of massive blood loss in women with placenta accreta. Am J Obstet Gynecol 2011;205:38.e1-6.

19. Pri-Paz S, Fuchs KM, Gaddipati S, Lu YS, Wright JD, Devine PC. Comparison between emergent and elective delivery in women with placenta accreta. J Matern Fetal Neonatal Med. 2013;26:1007-11.

20. Bowman ZS, Manuck TA, Eller AG, Simons M, Silver RM. Risk factors for unscheduled delivery in patients with placenta accreta. Am J Obstet Gynecol. 2014;210:e1-6.

21. Bowman ZS, Eller AG, Kennedy AM, Richards DS, Winter TC 3rd, Woodward PJ, et al. Accuracy of ultrasound for the prediction of placenta accreta. Am J Obstet Gynecol. 2014;211:e1-7.

22. Comstock CH, Love JJ Jr, Bronsteen RA, Lee W, Vettraino IM, Huang RR, et al. Sonographic detection of placenta accreta in the second and third trimesters of pregnancy. Am J Obstet Gynecol. 2004;190:1135-40.

23. Publications Committee, Society for Maternal-Fetal Medicine, Belfort MA. Placenta accreta. Am J Obstet Gynecol 2010;203:430-9. 